\title{
Awareness and Attitude of General and Specialist Dentists in Providing Oral Health-related Quality of Life for Children with Special Healthcare Needs
}

\author{
Konda Suhasini ${ }^{1}$, Rodda Rajashekhar ${ }^{2}$, Jampanapalli Sharada Reddy ${ }^{3}$, Inguva Hemachandrika ${ }^{4}$, Patloth Tarasingh ${ }^{5}$, \\ Hasanuddin Shaik ${ }^{6}$
}

\begin{abstract} dentists of various specialties were assessed through a structured questionnaire. in the management of these children.

Keywords: General dentists, Special healthcare children, Specialist dentist.

International Journal of Clinical Pediatric Dentistry (2021): 10.5005/jp-journals-10005-1968

\section{INTRODUCTION}

Oral healthcare for disabled children remains a challenge for a dentist. Most disabled children cannot find a professional resource to provide appropriate dental care. Healthcare for children with special needs requires specialized knowledge, increased awareness, attention, adaptation, and accommodative measures. ${ }^{1-4}$ Those most in need are still least able to respond, reflecting the "Inverse Care Law" of Hart. ${ }^{5}$ This study is carried out to assess the awareness and attitude of general dentists and specialty dentists in providing oral healthrelated quality of life for children with special healthcare needs.
\end{abstract}

Special healthcare needs children (SHCNC) requires specialized knowledge acquired by additional training, as well as increased awareness and accommodative measures on part of general practitioners and specialist dentists beyond what is considered routine. Most dentists face challenges in treating these children, due to lack of awareness and insufficient training regarding the management of such children in a dental operatory. Aim and objective: This study was undertaken to investigate the awareness, practices, and hurdles faced by general dentists and dentists of various specialties in providing oral healthcare to children with special healthcare needs.

Materials and methods: The study was conducted in dental colleges and private dental clinics in and around Hyderabad. General dentists and

Statistical analysis: The data obtained were analyzed with a Chi-square test (SPSS Version - 20).

Results: The study showed that $80 \%$ of the dentists were willing to treat these children, but lack of sufficient training has been the major hurdle

Conclusion: The training of dentists in taking care of children with special healthcare needs should be enhanced to provide comprehensive dental care to these children, thereby enabling them to realize their normal level of functioning and lengthening their life span.

\section{Materials and Methods}

The survey was conducted with a 30-item questionnaire answered by 317 registered dentists in Hyderabad. The validity of the questionnaire was confirmed with similar articles and with the help of our investigators. Most of the general and specialty dentists present in Hyderabad city during the time of the study were included in the study. The questions were formulated in such a way that, they help in assessing "the awareness regarding guidelines of the clinical setup for children with special healthcare needs among dentists, practices followed and hurdles faced by them in providing oral healthcare to such children, their specialization and years of experience in practising dentistry". The data obtained were analyzed with a Chi-square test (SPSS Version-20).

\section{Results}

Out of 350 survey forms distributed among general and specialty dentists, 317 were returned. Out of the 317 respondents, 59\%

\footnotetext{
${ }^{1-6}$ Department of Pedodontia, Government Dental College and Hospital, Hyderabad, Telangana, India

Corresponding Author: Patloth Tarasingh, Department of Pedodontia, Government Dental College and Hospital, Hyderabad, Phone: +91 9951749730, e-mail: dr_tara_singh@yahoo.com
}

How to cite this article: Suhasini K, Rajashekhar R, Reddy JS, et al. Awareness and Attitude of General and Specialist Dentists in Providing Oral Health-related Quality of Life for Children with Special Healthcare Needs. Int J Clin Pediatr Dent 2021;14(5):601-603.

Source of support: Nil

Conflict of interest: None

were females and $41 \%$ were males. Among all the practitioners, general dentists constitute $35 \%$ and specialty dentists constitute $65 \%$ (Fig. 1), out of which pedodontists were as high as $18 \%$ and prosthodontists were only $3 \%$ (Fig. 2). The data revealed that $60 \%$ of dentists encountered $<3$ number of special needs patients every month in their practice and $80 \%$ of dentists were willing to treat such patients. When the dentists were asked about the facilities provided at their clinics for special children, it was found that $60 \%$ of dentists clinics were located other than the ground floor and without ramps, $90 \%$ of dentists were not having any lift facility, and $95 \%$ of them are neither having any special dental chair for restraining the special children nor a wheelchair for shifting the patients to the general hospital in emergencies (Fig. 3). The various barriers encountered by the dentists in managing special children were level of disability and difficulty in communicating 
were scored as high as 92 and 90\%, respectively. Whereas lack of training in managing special children and attending a special course in managing special child constitutes for about 85 and $80 \%$, respectively (Fig. 4).

\section{Discussion}

According to this study, $35 \%$ of general dentists and $65 \%$ of specialty dentists treated patients with special care needs. Out of $65 \%$ of specialty dentists, pedodontists constituted about $10 \%$ and the remaining individual specialties constituted about $3-8 \%$ only. This may be due to increased awareness of pedodontists in managing special children as they are trained during their post-graduate course regarding management, special equipment/instruments required to overcome the difficulties in treating these children. Moreover, the majority of general dentists (78\%) are referring the special needs patients to pedodontists rather than treating them because of the requirement of more chairside time to manage and treat these patients. The time limitation is also a barrier agreed by $83 \%$ of the dentists in this study. A similar study had been reported by Nunn and Murray. ${ }^{6}$

The data of our survey also revealed that $60-95 \%$ of the dentists are not having facilities (ground floor, lift, wheelchair, special dental

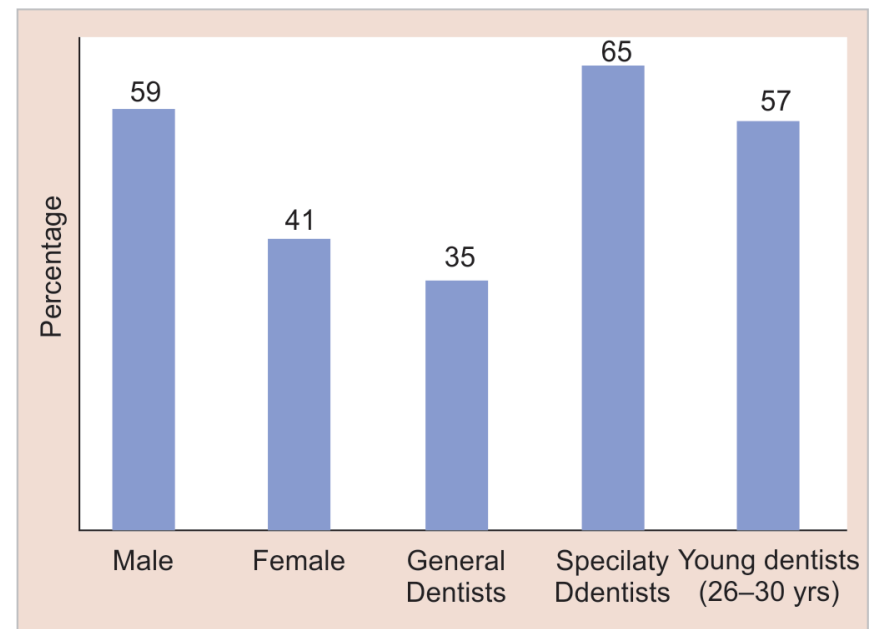

Fig. 1: Demographic data of study population chair) that are essential for access to and to accommodate children with special needs in their clinic. These data were found similar to a study done by Baird et al. ${ }^{7}$ The data revealed that the highest percentage of special healthcare needs children (SHCNC) patients in need of dental treatment repeated to their clinics with mental disabilities and least were those with systemic diseases. Whereas in a study done by Priyadarshini, patients with physical disabilities were more. ${ }^{8}$

The barriers for practitioners in providing oral health to SHCNC in this study were found to be a time constraint, anxious children, lack of knowledge regarding management techniques, level of disability, difficulty in communicating, and lack of training. These findings are partly similar to studies done by Rao et al. ${ }^{9}$ and Dao et al. ${ }^{10}$ who stated that lack of clinical training was the most difficult barrier in managing disabled children. Partly, the results are not in accordance with studies of Milano and Seybold who reported insufficient financial reimbursement as a major reason. ${ }^{11}$ The overall inference of the present study suggests that adequate facilities with an infrastructure request, proper academic programs like continuing dental education programs on SHCNC management, and hands-on training on management protocol could be carried out to overcome the barriers faced by dentists in treating these patients. The limitation of this study was that the data collected in

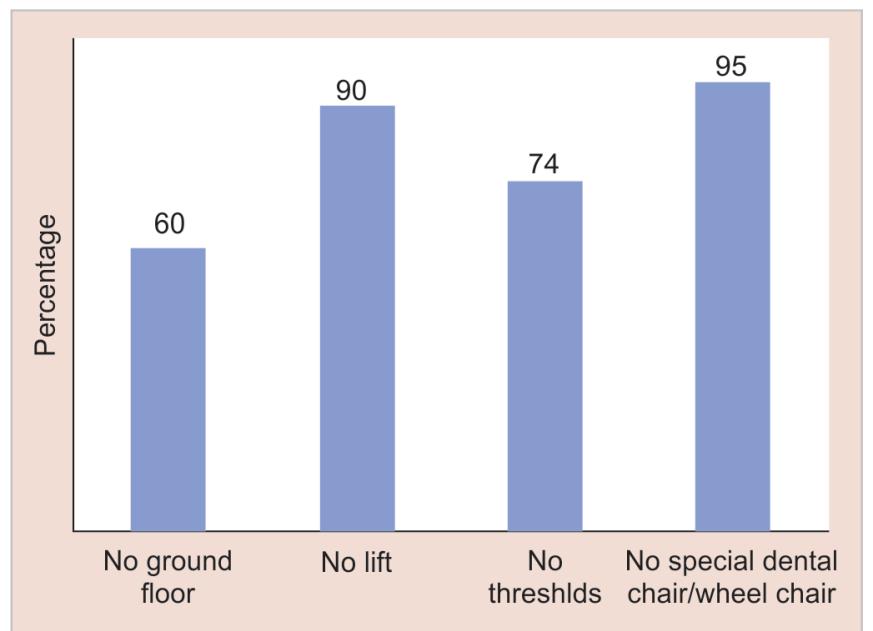

Fig. 3: Facilities at dental clinic for special children

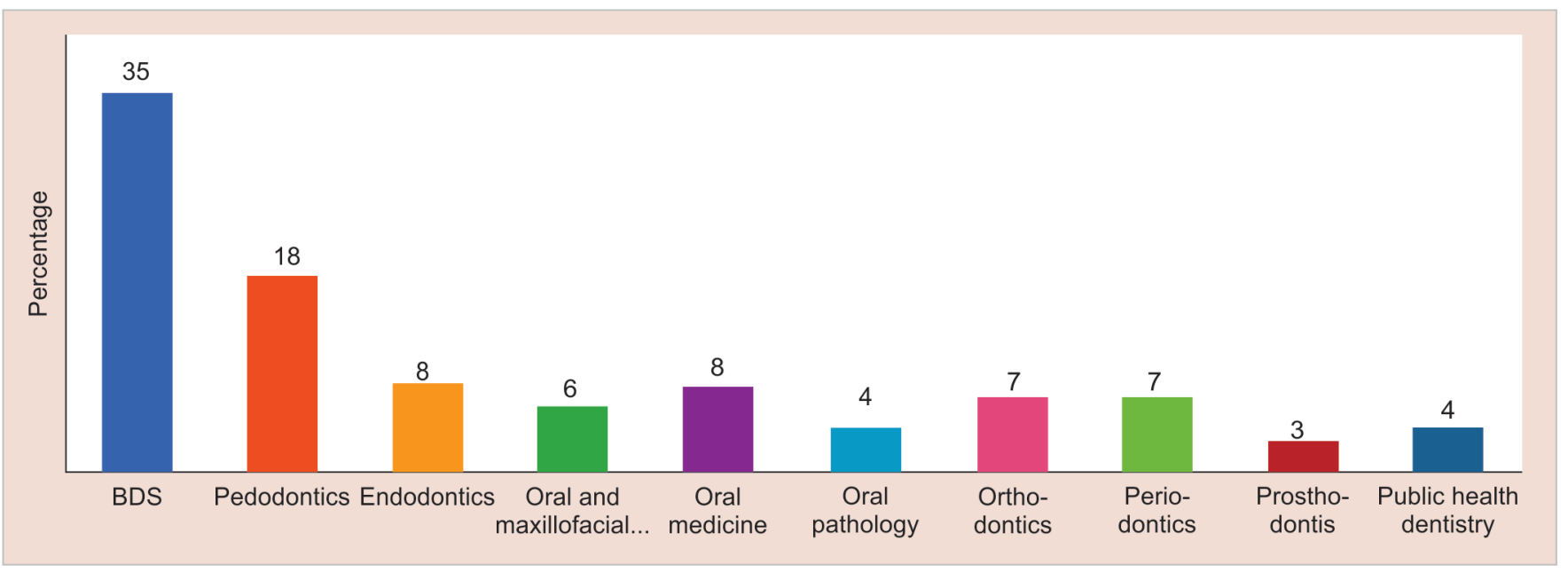

Fig. 2: Distribution of general and specialty dentists 


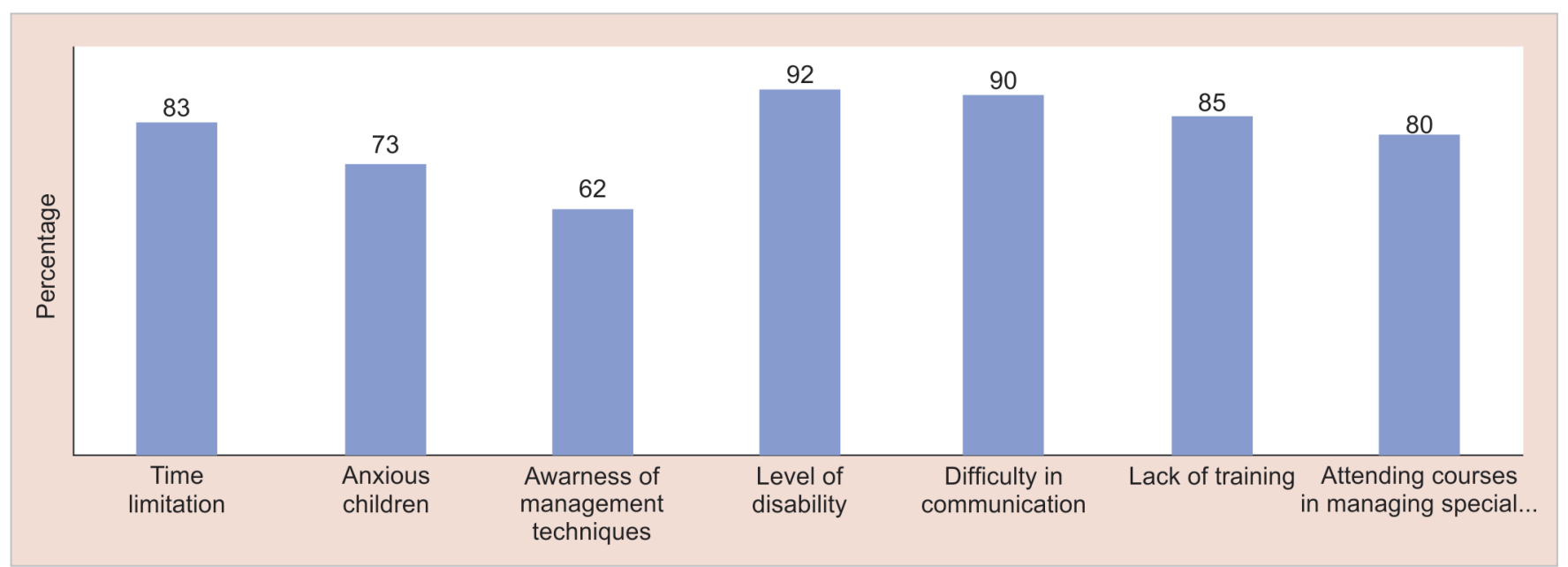

Fig. 4: Barriers to practitioners in providing oral healthcare for special children

this study were subjected to response bias and recall bias, also the variation in the specialty and years of experience of the participants.

\section{Conclusion}

Based on the findings of this study, few potential strategies like the incorporation of evidence-based education, continuing dental education programs, and hands-on training programs for the management of special needs patients from the undergraduate level can be proposed to combat the barriers and help the professionals meet the requirements of SHCNC. However, it is the individual preference of a general dentist or specialist dentist that determines the final treatment outcome for an SHCN child. There is an increasing need to develop and integrate interventions that are designed for children with special healthcare needs based on the recommendations by AAPDsponsored symposium "Lifetime Oral Healthcare for Patients with Special Needs".

\section{References}

1. Halberg U, Strandmark M, Klingberg G. 'Dental health professionals' treatment of children with disabilities: a qualitative study. Acta Odontol Scand 2004;62(6):319-327. DOI: 10.1080/00016350410001810.

2. Halberg U, Klingsberg G. Medical health care professionals' assessments of oral health needs in children with disabilities: a qualitative study. Eur J Oral Sci 2005;113(5):363-368. DOI: 10.1111/j.1600-0722.2005.00238.x.

3. Owens BL, Kirker BD, Zigler E, et al. Vision and oral health needs of individuals with an intellectual disability. Ment Retard Dev Disabilit Res Rev 2006;12(1):28-40. DOI: 10.1002/mrdd.20096.

4. Nunn JH. The burden of oral ill health for children. Archives Dis Childhood 2006;91(3):251-253. DOI: 10.1136/adc.2005.077016.

5. Hart JT. The inverse care law. Lancet 1971;1(7696):405-412. DOI: 10.1016/s0140-6736(71)92410-x.

6. Nunn JH, Murray JJ. Dental care of handicapped children by general dental practitioners. J Dent Heal Edu 1998;52(8):463-465. DOI: 10.1002/j.0022-0337.1988.52.8.tb02220.x.

7. Baird WO, Grother MC, Abrams KR, et al. Access to dental services for people with a physical disability: a survey of general dental practitioners in Leicestershire, UK. Community Dent Heal 2008;25(4):248-252.

8. Priyadarshini B, Lin CN, Umesh B, et al. Dental treatment of special needs patients: dentists point of view in selected cities of Malaysia. Biomed Res 2015;26(1):152-156.

9. Rao D, Amitha H, Munshi AK. Oral hygiene status of disabled children and adolescents attending special schools of South Canara, India. Hong Kong Dent J 2005;2:107-112.

10. Dao LP, Zwetchkenbaum S, Inglehart MR. General dentists \& special needs patients. Does dental education matters? J Dent Educ 2005;69(10):1107-1115. DOI: 10.1002/j.0022-0337.2005.69.10. tb04011.x.

11. Milano M, Seybold SV. Dental care for special needs patients: a survey of Texas pediatric dentists. ASDC J Dent Child 2002;69(2):212-215. 